\title{
Phenology and fitness of Calanus glacialis, C. finmarchicus (Copepoda), and their hybrids in the St. Lawrence Estuary
}

\author{
Geneviève J. Parent ${ }^{1, *}$, Stéphane Plourde ${ }^{2}$, Pierre $\mathrm{Joly}^{2}{ }^{2}$ Julie Turgeon ${ }^{1}$ \\ ${ }^{1}$ Québec-Océan, Département de Biologie, Université Laval, Quebec City, Quebec, Canada \\ ${ }^{2}$ Maurice-Lamontagne Institute, Fisheries and Oceans Canada, Mont Joli, Quebec, Canada
}

\begin{abstract}
Hybrids between 2 abundant copepod species, Calanus glacialis and C. finmarchicus, were recently detected along the Atlantic and Arctic Canadian coast. Hybridization may affect population dynamics and, thus, impact local productivity. Our study aims to characterize the effect of hybridization on Calanus demography by comparing the in situ reproductive phenology and fitness of parental species and their hybrids. Environmental conditions were monitored and adult Calanus females were sampled in the upper layer in the St. Lawrence Estuary every second week from the pre-bloom (March to May) to bloom period (June to July) in 2010. Maximal abundance of hybrids (17\%) occurred in April between the maxima of C. glacialis (March) and C. finmarchicus (June). The different reproductive phenology of hybrids and parental species likely reduces interspecific gene flow. Contrastingly, fitness components such as the egg production rate of hybrids matched those of their maternal ancestor over the sampling interval. Still, hybrids represented only $10 \%$ of total abundance, and their population-based egg production rate was always smaller than that of one parental species. The pre-bloom conditions during the peak abundance of hybrids may partially explain their small reproductive output in that area. Consequently, the impact of hybridization on the parental species' population size seems small in 2010 in the St. Lawrence Estuary. However, long-term and spatial surveys are required to conclude on the general effect of hybridization on the population size of parental species over the vast area where they co-occur.
\end{abstract}

KEY WORDS: Life history traits - Reproductive output - Egg production rate - Females - Copepod . Hybridization

*Corresponding author: genevieve.parent.5@ulaval.ca

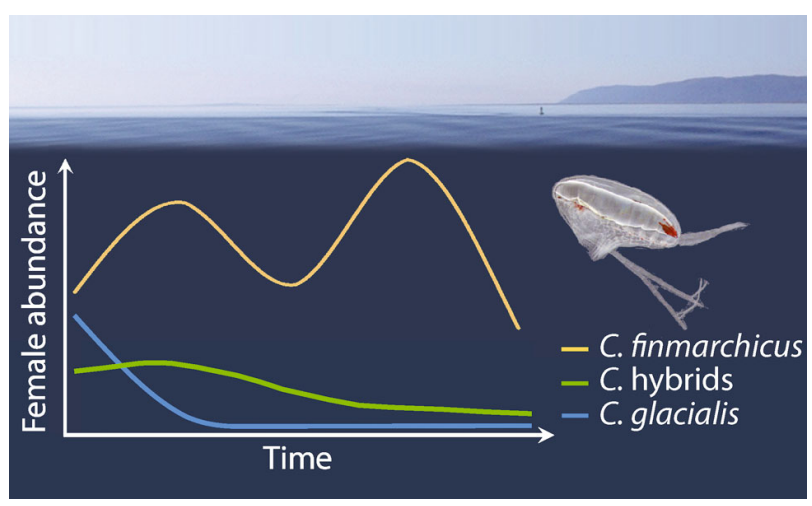

Reproductive phenology of Calanus glacialis, C. finmarchicus (photo) and their hybrids in the St. Lawrence Estuary from March to July.

Image: G. J. Parent

\section{INTRODUCTION}

Marine copepod species exhibit a variety of life histories in response to annual periodicity (e.g. Conover 1988, Conover \& Huntley 1991, Atkinson 1998, Schnack-Schiel 2001). Within the same environment, it is widely held that congener species of copepods have unique assortments of life-history traits, limiting interactions among them. Differences are frequently observed in key life-history traits related to diapause and reproduction (Miller 2004, Varpe 2012). Variations in these key traits are associated with periodicity in abiotic conditions and food availability for copepod species from the Northern Hemisphere.

The reproductive phenology of the Arctic Calanus glacialis Jaschnov 1955 differs from that of the North Atlantic C. finmarchicus (Gunnerus, 1770). In sympa- 
try, the reproductive phenology of C. glacialis precedes that of C. finmarchicus (Madsen et al. 2001, Plourde et al. 2001). For instance, in the St. Lawrence Estuary, C. glacialis and C. finmarchicus lay eggs near the surface in late winter and late spring, respectively (Plourde et al. 2001, S. Plourde unpubl. data). These different phenologies are related to alternative strategies of energy utilization to lay eggs. C. glacialis females generally initiate reproduction before the phytoplankton bloom (Daase et al. 2013), using lipid reserves or feeding on ice algae to support moderate egg production rates (Smith 1990, Tourangeau \& Runge 1991, Hirche \& Kattner 1993, Kosobokova \& Hirche 2001). In C. finmarchicus, the majority of females captured prior to the spring bloom do not lay eggs, suggesting that external energy sources are necessary for gonad maturation and egg production in this species (Plourde \& Runge 1993).

Recently, interspecific hybrids between C. glacialis and $C$. finmarchicus were identified at copepodite Stage V (CV) from the Canadian Archipelago (north) to the Gulf of Maine (south) (Parent et al. 2012). The presence of hybrids raises questions about their life-cycle strategies and phenology, including their reproductive strategy relative to those of their parental species. Parent et al. (2012) inferred hybrid reproductive phenology from indirect evidence based on a temporal series of samples from 1 site in the St. Lawrence Estuary. Using birth date of CV estimated with backward calculation based on the developmental time of C. finmarchicus (Campbell et al. 2001), Parent et al. (2012) suggested that hybrids possibly lay eggs early in the spring, between the parental species' main spawning periods. However, such estimates using development time of $C$. finmarchicus may not be adequate for hybrids.

Population sizes of C. finmarchicus and C. glacialis may be affected by hybridization if hybrids have inferior, equivalent, or superior fitness to parental species. Indeed, hybridization can act as a source or sink in population dynamics. Numerous studies have shown that hybrid fitness is variable (reviewed by Arnold \& Hodges 1995, Seehausen 2004). For the marine copepod Tigriopus californicus, firstgeneration hybrids between highly divergent populations have equal or sometimes slightly higher fitness (estimated based on survival) than their parents in experimental crosses (Edmands 1999). In contrast, hybrids between Mytilus edulis and M. galloprovincialis have lower fitness than the parental species (Bierne et al. 2002). Parent et al. (2012) suggested that the fitness of C. finmarchicus and C. glacialis hybrids is not null. Introgressed individuals were observed at late copepodite stages, indicating that some hybrids reach the adult stage and are fertile. However, a comparative study of parental species and hybrid fitness is crucial to clarify the potential effect of hybridization on local productivity.

This study aims to characterize and compare the reproductive phenology and fitness of female $\mathrm{C}$. glacialis, C. finmarchicus, and their hybrids under naturally varying environmental conditions between late winter and summer. In situ fitness comparisons will allow a better understanding of the impact of hybridization on species population size and thus on local productivity. To do so, we collected adult females on multiple occasions between early March and early July during the reproductive periods of C. glacialis and C. finmarchicus at Rimouski Station in the St. Lawrence Estuary, and we compared important fitness-related traits.

\section{MATERIALS AND METHODS}

\section{Sampling}

Environmental conditions were assessed and zooplankton was sampled every second week from early March to the end of July 2010 at Rimouski Station in the lower St. Lawrence Estuary $\left(48^{\circ} 40^{\prime} \mathrm{N}, 68^{\circ} 35^{\prime} \mathrm{W}\right.$, Plourde et al. 2001) (Table 1). This temporal sampling series was especially fruitful because of an exceptionally early start of sampling in late winter due to favourable (low) ice conditions (Galbraith et al. 2012). At this station, a long-term monitoring program initiated in 1991 allows for interannual comparison of environmental conditions and zooplankton species abundances. Environmental data were collected vertically, from the surface to 5 to $10 \mathrm{~m}$ above the bottom (ca. $320 \mathrm{~m}$ ), using a conductivity-temperature-depth (CTD) sensor lowered continuously at a targeted speed of $1 \mathrm{~m} \mathrm{~s}^{-1}$ to within $5 \mathrm{~m}$ of the bottom. Water was collected with 51 Niskin bottles at 8 depths $(0,5,10,15,20,25,35$, and $50 \mathrm{~m})$.

Zooplankton were sampled with a $200 \mu \mathrm{m}$ mesh net towed vertically from 100 or $125 \mathrm{~m}$ to the surface and diluted in 41 plastic jars filled with filtered sea water. Our study therefore targeted the active component of Calanus spp. above the diapausing component occupying the 150 to $300 \mathrm{~m}$ depth layer (Plourde et al. 2001). According to their prevalent $2 \mathrm{yr}$ life cycle, C. glacialis females captured in our study probably recruited from $\mathrm{CV}$ during the previous growth season in summer and overwintered (Conover 1988), whereas the majority of $C$. finmarchicus females cap- 
Table 1. Sampling dates, adult female genetic identification, and total abundance estimate at Rimouski Station in 2010. The number of genotypes classified as Calanus glacialis $\left(\mathrm{G}^{9}\right)$, hybrid with C. glacialis mtDNA $\left(\mathrm{H}^{\mathrm{9}}\right)$, hybrid with $C$. finmarchicus mtDNA $\left(\mathrm{H}^{\mathrm{f}}\right)$, and $C$. finmarchicus $\left(\mathrm{F}^{\mathrm{f}}\right)$ are given for each station. ${ }^{*}$ One $\mathrm{F}^{\mathrm{g}}$ individual was identified in this sample

\begin{tabular}{|c|c|c|c|c|c|c|}
\hline \multirow{2}{*}{$\begin{array}{l}\text { Sampling date } \\
\text { (dd/mm/уууу) }\end{array}$} & \multirow{2}{*}{$\begin{array}{c}\text { Total } \\
\mathrm{n}\end{array}$} & \multicolumn{4}{|c|}{ Genetic identification } & \multirow{2}{*}{$\begin{array}{l}\text { Total abundance } \\
\text { (females } \mathrm{m}^{-2} \text { ) }\end{array}$} \\
\hline & & $\mathrm{G}^{\mathrm{g}}$ & $\mathrm{H}^{g}$ & $\mathrm{H}^{\mathrm{f}}$ & $\mathrm{F}^{\mathrm{f}}$ & \\
\hline $12 / 03 / 2010$ & 48 & 22 & 4 & 2 & 20 & 881 \\
\hline $22 / 03 / 2010$ & 48 & 16 & 1 & 5 & 26 & 985 \\
\hline 07/04/2010 & 48 & 1 & 6 & 6 & 35 & 838 \\
\hline $21 / 04 / 2010$ & $48^{*}$ & 0 & 1 & 2 & 44 & 996 \\
\hline 05/05/2010 & 48 & 0 & 1 & 7 & 40 & 631 \\
\hline $18 / 05 / 2010$ & 48 & 0 & 0 & 2 & 46 & 453 \\
\hline 03/06/2010 & 46 & 0 & 1 & 0 & 45 & 985 \\
\hline 16/06/2010 & 47 & 0 & 0 & 2 & 45 & 905 \\
\hline 07/07/2010 & 47 & 0 & 0 & 2 & 45 & 566 \\
\hline $21 / 07 / 2010$ & 48 & 0 & 0 & 3 & 45 & 120 \\
\hline Total n & 476 & 39 & 14 & 31 & 391 & \\
\hline
\end{tabular}

tured in late winter and spring had probably recently molted from diapausing CV representing the bulk of the overwintering population in a typical $1 \mathrm{yr}$ life cycle (Plourde et al. 2001). Water samples and zooplankton were maintained at 5 to $6^{\circ} \mathrm{C}$ in coolers during transport to the laboratory at the Maurice Lamontagne Institute (Mont-Joli, Canada). At the end of the incubation experiments (see 'Fitness' below), live animals $(n=476)$ were photographed and then frozen individually at $-80^{\circ} \mathrm{C}$ for genetic characterization. The remainder of the zooplankton samples was preserved in $4 \%$ formalin solution for abundance estimation.

\section{Environmental conditions}

Within 1 to $3 \mathrm{~h}$ of sampling, subsamples of 250 to $750 \mathrm{ml}$ from each water bottle were filtered on GF/F filters. The filters were placed in $95 \%$ acetone, and chl $a$ was extracted at $5^{\circ} \mathrm{C}$ for 16 to $24 \mathrm{~h}$. Extracts were analyzed on a Turner Designs Model 112 fluorometer, and chl a concentrations were calculated in accordance with Parsons et al. (1984) and integrated over the depth sampled (0 to $50 \mathrm{~m}$ ). CTD data were verified and processed using standard quality control techniques (Emery \& Thomson 1997).

\section{Reproductive phenology}

The frequency of parental and hybrid genotypes was determined for each sample. Females were genetically characterized for speciesspecific variation at mtDNA (16S) and nuclear DNA loci (10 microsatellites) following the methods detailed by Parent et al. (2012). Each individual was assigned to 1 of 6 composite genotypes combining nuclear genotype (C. glacialis, C. finmarchicus, or hybrid) and mitochondrial haplotypes (C. glacialis or C. finmarchicus). To describe these composite genotypes (hereafter 'genotypes'), the nuclear component is represented by a capital letter, and the mitochondrial type is shown as a superscript (e.g. $\mathrm{H}^{\mathrm{f}}$ for a nuclear hybrid with $C$. finmarchicus mtDNA).

To determine the abundance of each genotype in each sample, the joint abundance of C. glacialis and C. finmarchicus was first estimated as part of the routine analysis of zooplankton species and stage composition using the formalin-preserved samples. In each sample, no less than $1 \%$ of all zooplankton was identified (between 300 and 600 individuals). Females with prosome length from 2.2 to $4.5 \mathrm{~mm}$ were classified as C. finmarchicus or C. glacialis (Unstad \& Tande 1991) and counted to provide a joint abundance estimate. In each sample, the abundance of each genotype was then estimated by multiplying its estimated frequency by the joint abundance estimate. The relative abundance of each genotype was also calculated each month and across the entire sampling period.

\section{Fitness}

Within 1 to $3 \mathrm{~h}$ of sampling, ca. 48 Calanus adult females (excluding the larger and easily distinguishable $C$. hyperboreus) were sorted from the live zooplankton catch, representing the relative proportions of C. glacialis and C. finmarchicus. These females were kept individually in $60 \mathrm{~mm}$ diameter polystyrene Petri dishes filled with $0.2 \mu \mathrm{m}$ filtered seawater. Females were incubated for $24 \mathrm{~h}$ in the dark at a temperature representative of the surface layer (March to early April: 1 to $2^{\circ} \mathrm{C}_{\text {; }}$ late April to July: 4 to $6^{\circ} \mathrm{C}$ ) to measure the in situ egg production rate (EPR) (Runge \& Roff 2000, Plourde et al. 2001).

Four fitness components were estimated based on these incubations. EPR was calculated as the number of eggs produced per female per day, i.e. including females that did not lay eggs. The other 3 fitness 
components were estimated only for egg-laying females. Clutch size was measured as the number of eggs produced per female. The egg hatching success (\%) and viability (\%) were estimated by incubating eggs for an additional $72 \mathrm{~h}$ until hatching. Egg hatching success was calculated as the ratio of the number of all nauplii over all eggs laid, whereas egg viability excluded non-viable nauplii, i.e. deformed or dead. In addition to these individual parameters, we estimated the contribution of each genotype to the egg production rate of the population (pEPR) by multiplying the mean EPR of each genotype by the abundance of this genotype. Relative pEPR was then estimated each month to be used as a measure of relative fitness.

Two phenotypic traits related to reproductive status were also assessed: gonad development and lipid reserve. These traits may be useful to interpret results on fitness because they may partially explain or confirm the reproductive status of each individual female (Plourde \& Runge 1993). After the incubation period, females were laterally positioned and photographed with a camera attached to a dissecting microscope. Gonad development index (GDI) was evaluated from the photograph using the 4 stages of gonad development (GS1 to GS4) described by Niehoff \& Hirche (1996), with GS3 and GS4 being indicative of actively reproducing adult females. Lipid reserves were estimated as the ratio between the ellipsoid lipid volume $\left(V_{\mathrm{O}}=2 / 3 A w\right)$ over the ellipsoid animal volume $\left(V_{\mathrm{B}}=1 /{ }_{6} \pi L w^{2}\right)$ (Vogedes et al. 2010). Prosome length ( $L$, the distance from the tip of the cephalosome to the tip of the last thoracic segment), prosome width ( $w$, the distance between each side of the cephalosome second segment), and lipid reserve area $(A)$ were measured with ImageJ v. 1.45.

\section{Statistical analyses}

The 2 samples from each month were pooled to increase sample size in analyses of variance (ANOVAs). Sample sizes varied from zero to 90 for fitness components and traits related to reproductive status. To minimize the impact of an experimental design with missing values and unequal sample size, we used ANOVAs of Type IV to compare these variables within a month among genotypes and across months within genotype. Tukey-Kramer post-hoc tests were then used for group comparisons when sample sizes were $\geq 3$. Normality and homogeneity of variance were evaluated graphically. Square root transformations were necessary for EPR and lipid reserve ratio.
Statistical analyses were carried out using SAS software v.9.2.

\section{RESULTS}

\section{Environmental conditions}

The sampling interval covered 2 periods characterized by contrasting environmental conditions. Both temperature and chl a biomass increased from March to July (Fig. 1). Mean surface temperature (0 to $50 \mathrm{~m}$ ) increased from March to July. Chl a biomass was low from March to May and then increased considerably in June and again in July (Fig. 1). This pattern can be summarized as a pre-bloom period (March to May) characterised by cold conditions and low chl a biomass ( $<50 \mathrm{mg} \mathrm{m}^{-2}$ ), and a bloom period (June to July) marked by warmer temperatures and higher chl a biomass (>50 $\mathrm{mg} \mathrm{m}^{-2}$ ) (Fig. 1). The onset of the bloom in June perfectly matches the timing previously reported by Plourde \& Runge (1993) and falls within the long-term seasonal climatology in environmental conditions in the region (Plourde et al. 2001, 2009a).

\section{Reproductive phenology}

The reproductive periods of both parental species, as well as hybrids, were covered at least partially. Females with 5 different genotypes were identified in the surface layer ( 0 to $100 \mathrm{~m}$ or 0 to $125 \mathrm{~m}$ ) during the sampling interval (Table 1). Parental species

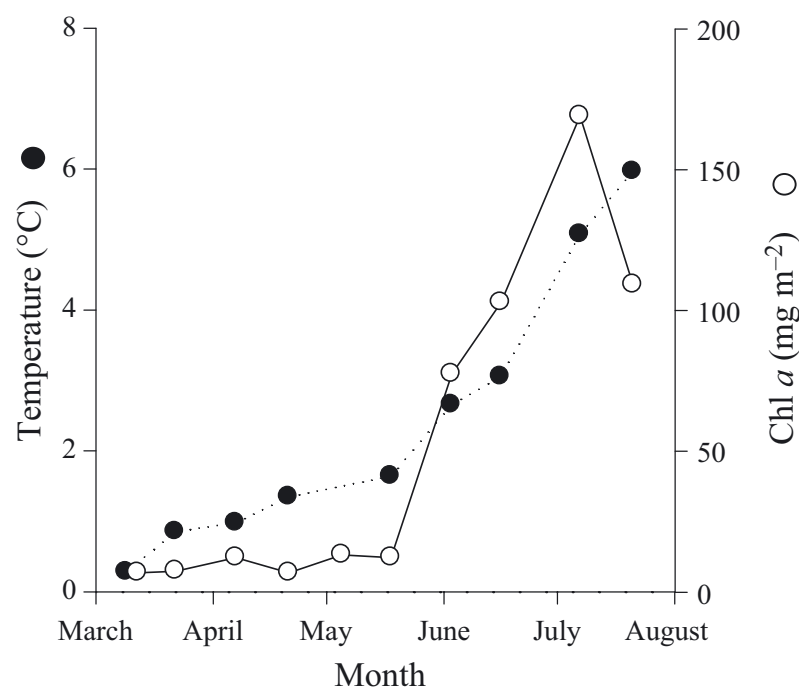

Fig. 1. Variability of environmental characteristics from March to July at Rimouski Station in 2010 in the 0 to $50 \mathrm{~m}$ depth zone 

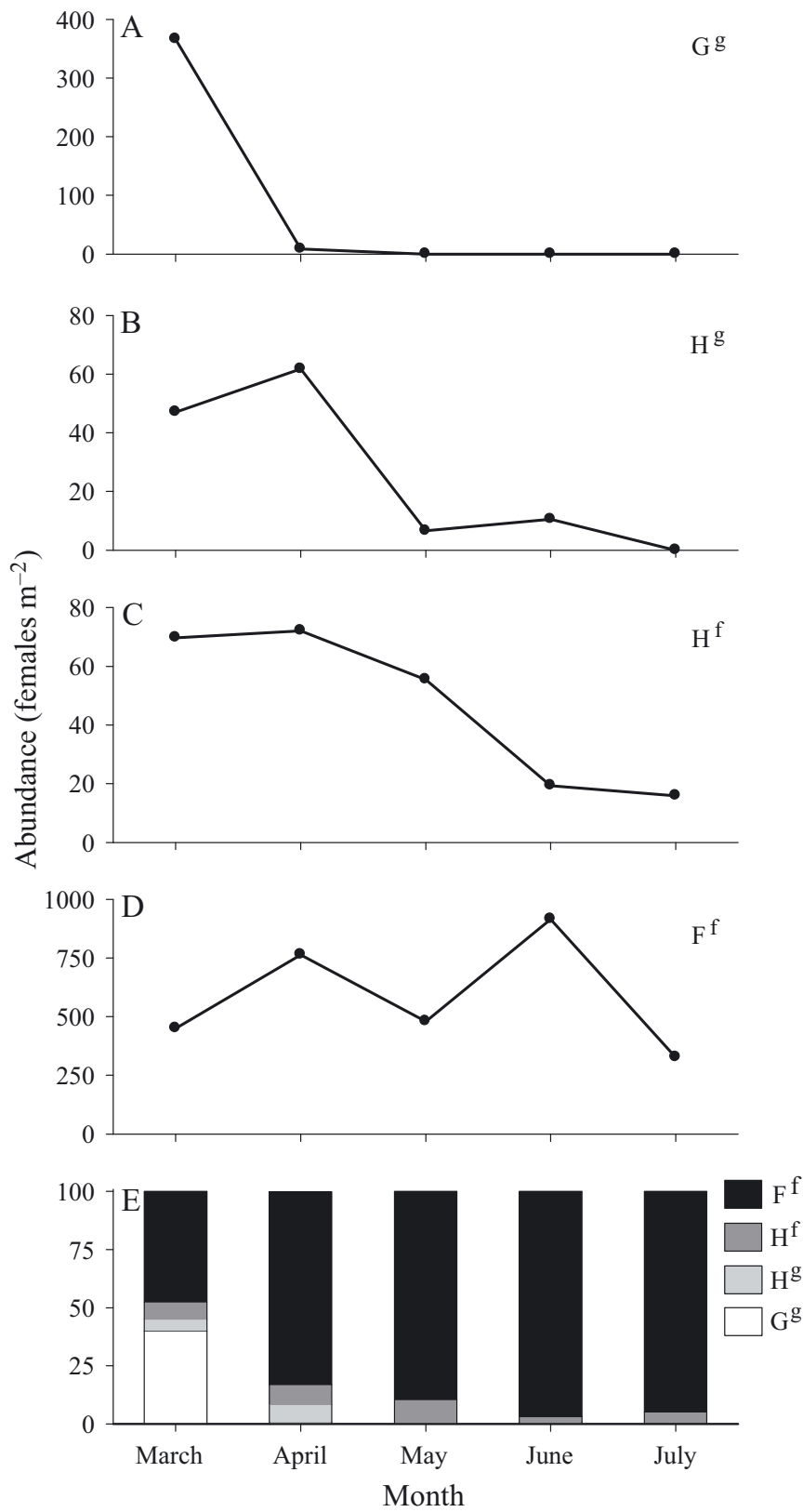

Fig. 2. Temporal variability of (A-D) genotypic abundance and (E) monthly relative abundance at Rimouski Station in 2010. Genotypes are identified as in Table 1. The single Fg individual is not shown (Table 1)

dominated the samples, with $82 \%$ C. finmarchicus (n=391) and $8 \%$ C. glacialis $(\mathrm{n}=39)$. Overall, hybrid frequency was $10 \%(\mathrm{n}=46)$, with $\mathrm{H}^{\mathrm{g}}(3 \%, \mathrm{n}=14)$ and $\mathrm{H}^{\mathrm{f}}(6 \%, \mathrm{n}=31)$ hybrids dominating. Only 1 highly introgressed hybrid was observed ( $\mathrm{F}^{\mathrm{g}}, \mathrm{n}=1$ ) (Table 1). Relative to their maternal ancestor, hybrids with $C$. glacialis mtDNA were more frequent than those with C. finmarchicus mtDNA (Table $1 ; \mathrm{H}^{\mathrm{g}} / \mathrm{G}^{\mathrm{g}}$ : 0.36, $\mathrm{H}^{\mathrm{f}} / \mathrm{F}^{\mathrm{f}}$ : 0.08).
C. glacialis, C. finmarchicus, and hybrids displayed distinct temporal patterns of abundance during the sampling interval (Fig. 2). C. glacialis was present only during the pre-bloom period, with maximal abundance in March (366 females $\mathrm{m}^{-2}$ ) (Fig. 2A). By contrast, $C$. finmarchicus was abundant during both the pre-bloom and bloom periods and attained maximal abundance in June (915 females $\mathrm{m}^{-2}$ ) (Fig. 2D). Hybrids with C. glacialis and C. finmarchicus mtDNA were also observed during pre-bloom and bloom periods (Fig. 2B,C), reaching their maximal proportion of Calanus spp. females at $16.6 \%$ in April (Fig. 2E). The single $\mathrm{F}^{\mathrm{g}}$ genotype was observed in April. This female did not lay eggs and will not be considered any further.

\section{Fitness}

The 2 parental species co-occurred only in March, and C. glacialis then displayed higher fitness (Table 1, Fig. 3). During that month, C. glacialis displayed higher EPR ( $\mathrm{df}=3, F=8.8, \mathrm{p}<0.0001$, Fig. 3A) and GDI (df = 3, $F=8.0, \mathrm{p}<0.0001$, Fig. 3B) than $C$. finmarchicus. Lipid reserve ratio (Fig. 3C), clutch size, egg hatching success, and egg viability were not different between species (Fig. 3C, Table 2).

No statistically significant differences were detected between any of the fitness indices for hybrids and their maternal ancestors during any month (Fig. 3). Hybrids were less abundant than expected from previous observations in the St. Lawrence Estuary (Parent et al. 2012). Still, sample sizes were large enough to allow for comparisons between genotypes within 4 months using a statistical approach limiting the impact of missing values and variable sample sizes (see 'Materials and Methods'). In March, the EPR of hybrid genotypes were not statistically different from that of their maternal ancestor (Fig. 3A). During that month, GDI values for hybrid genotypes were not different from parental species values (Fig. 3B). There were no significant differences between hybrid and parental genotypes for lipid reserve ratio (Fig. 3C), clutch size, egg hatching success, and egg viability in March (Table 2). During the other months, no significant differences were found for any of the fitness indices between hybrid and parental genotypes, when sample sizes were large enough to permit statistical analysis (Fig. 3A-C, Table 2).

Fitness estimates could be compared across months for $C$. finmarchicus and 1 hybrid genotype $\left(\mathrm{H}^{\mathrm{f}}\right)$. For C. finmarchicus, $\mathrm{EPR}(\mathrm{df}=4, F=23.4, \mathrm{p}<0.0001)$, 

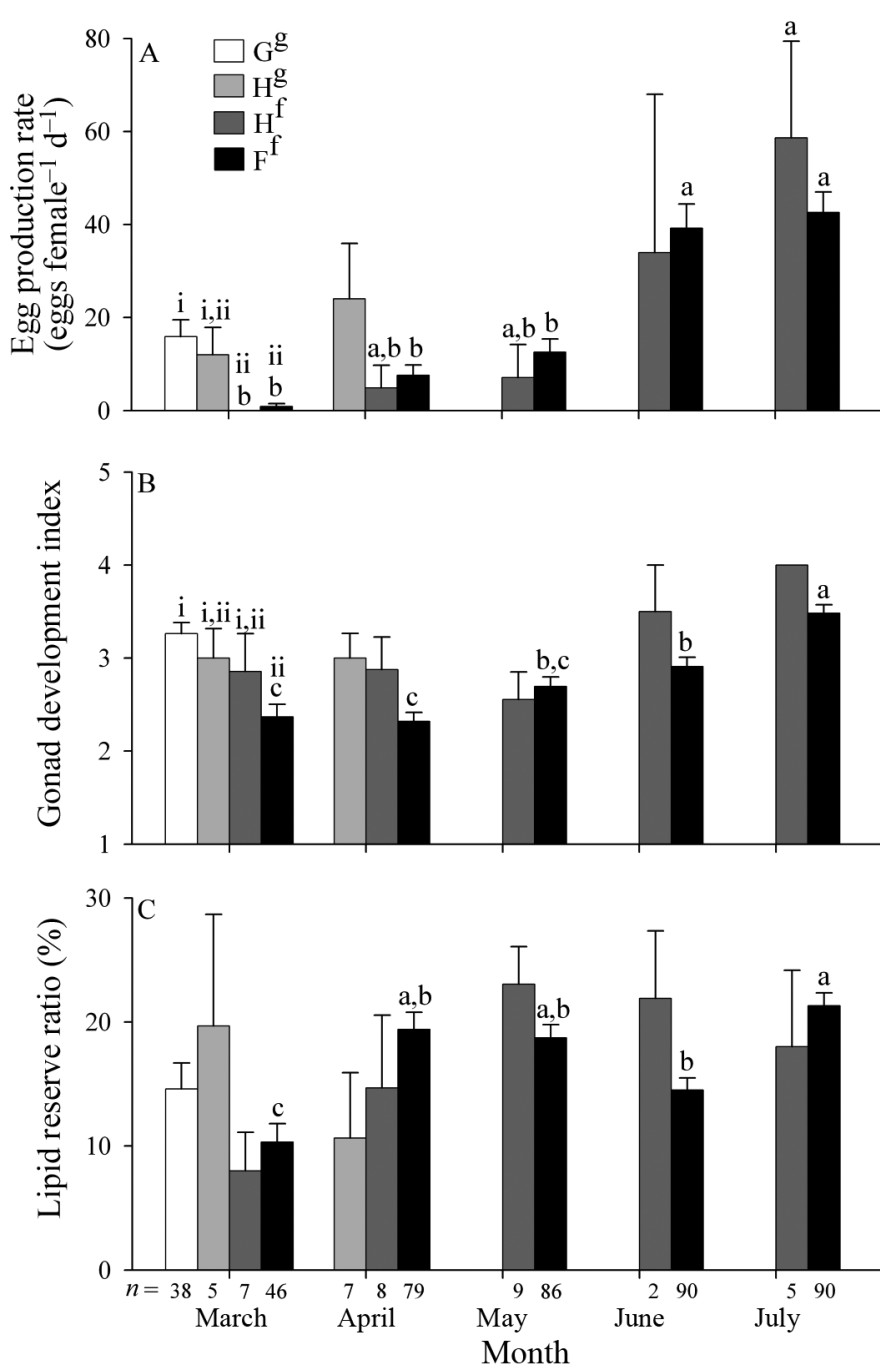

Fig. 3. Temporal variability of reproductive output at Rimouski Station in 2010 (mean \pm SE). Genotypes are identified as in Table 1. Different small letters above bars indicate values that are significantly different from one another within a month (e.g. i, ii) or across months (e.g. a, b) (TukeyKramer, $\mathrm{p}<0.05$ ). Only samples with size $\geq 3$ are considered for statistical analyses

clutch size $(\mathrm{df}=3, F=5.5, \mathrm{p}=0.0013)$, and GDI $(\mathrm{df}=4, F=19.51, \mathrm{p}<0.0001)$ varied significantly, increasing significantly from March to July (Fig. 3A,B, Table 2). Lipid reserve ratio also changed significantly (df $=4, F=11.1, \mathrm{p}<0.0001)$, increasing significantly from March to April and staying relatively high for the rest of the sampling period (Fig. 3C). Hybrids bearing $C$. finmarchicus mtDNA $\left(\mathrm{H}^{\mathrm{f}}\right)$ displayed a significant increase in EPR from March to July (df $=4, F=5.3, \mathrm{p}=0.003$ ) (Fig. 3A); a similar trend was observed for $C$. finmarchicus.

The population-based egg production rate $(\mathrm{pEPR}$, i.e. abundance multiplied by mean EPR of a geno- type) of hybrids and parental species peaked during different months. The pEPR of C. glacialis and $\mathrm{H}^{\mathrm{g}}$ was maximal in March (Fig. 4A) and April (Fig. 4B), whereas those of $\mathrm{H}^{\mathrm{f}}$ and $C$. finmarchicus were maximal in July (Fig. 4C) and June (Fig. 4D). For both parental species and $\mathrm{H}^{g}$, the timing of maximal $\mathrm{pEPR}$ coincided with maximal abundance (Figs. 2A,D \& $4 \mathrm{~A}, \mathrm{D})$. In contrast, maximal $\mathrm{pEPR}$ of $\mathrm{H}^{\mathrm{f}}$ occurred in July, whereas this genotype was most abundant earlier in April (Figs. 2C \& 4C). The combined pEPR of hybrid genotypes $\left(\mathrm{H}^{\mathrm{f}}\right.$ and $\mathrm{H}^{\mathrm{g}}$ ) was highest in April $\left(23 \%\right.$, Fig. 4 E) and mostly accounted for by $\mathrm{H}^{\mathrm{g}}(19 \%)$. Over the whole sampling interval, the contribution of each genotype to the total pEPR was major ( $86 \%$ ) for C. finmarchicus and minor for C. glacialis (8\%) and hybrids $(6 \%)$, with $\mathrm{H}^{\mathrm{g}}$ and $\mathrm{H}^{\mathrm{f}}$ sharing an equal contribution.

\section{DISCUSSION}

\section{Reproductive phenology}

Calanus glacialis and C. finmarchicus have different reproductive phenologies in the St. Lawrence Estuary. First, adult females of each species were most abundant in the surface layer (0 to $100 \mathrm{~m}$ or to $125 \mathrm{~m}$ ) at different times during the sampling interval; C. glacialis and C. finmarchicus females were most abundant in March and June, respectively. Second, the maximal EPR of each species was observed during different periods corresponding to different environmental conditions. C. glacialis had maximal EPR during the pre-bloom conditions, while that of $C$. finmarchicus was maximal during bloom conditions. These observations confirm the differences observed between these species in sympatry. For instance, $C$. glacialis lay eggs earlier than $C$. finmarchicus during pre-bloom conditions in Disco Bay, Greenland (e.g. Madsen et al. 2001). EPR is also lower for C. finmarchicus than for C. glacialis under starving conditions in the spring (Pasternak et al. 2013). Thus, our results confirm expected differences in reproductive phenology for these Calanus species.

In the St. Lawrence Estuary, the distinct but overlapping reproductive phenologies of C. glacialis and C. finmarchicus provide a critical temporal window for hybridization in the spring. Reproductively active C. glacialis and C. finmarchicus females were present at the surface in March and April. In March, the abundance of each species in the surface layer was comparable, but gonad development and EPR were higher in C. glacialis. Still, both species laid eggs, 
Table 2. Temporal variability of fitness components estimated for laying females at Rimouski Station in 2010 (mean \pm SE). Genotypes are identified as in Table 1. Different small letters indicate values that are significantly different across months (only samples with size $\geq 3$ are used for statistical analyses, Tukey-Kramer, $\mathrm{p}<0.05$ )

\begin{tabular}{|c|c|c|c|c|}
\hline $\begin{array}{l}\text { Hybrid } \\
\text { Month }\end{array}$ & $\begin{array}{c}\text { Laying } \\
\text { females (n) }\end{array}$ & $\begin{array}{l}\text { Clutch size } \\
\left(\text { eggs female }{ }^{-1}\right)\end{array}$ & $\begin{array}{l}\text { Egg hatching } \\
\text { success (\%) }\end{array}$ & $\begin{array}{c}\text { Egg viability } \\
(\%)\end{array}$ \\
\hline \multicolumn{5}{|l|}{$\mathbf{G}^{\mathbf{g}}$} \\
\hline Mar & 15 & $40 \pm 4$ & $81 \pm 9$ & $78 \pm 9$ \\
\hline Apr & 1 & 82 & 96 & 96 \\
\hline May & 0 & - & - & - \\
\hline Jun & 0 & - & - & - \\
\hline Jul & 0 & - & - & - \\
\hline \multicolumn{5}{|l|}{$\mathbf{H}^{\mathrm{g}}$} \\
\hline Mar & 3 & $20 \pm 6$ & $97 \pm 1$ & $96 \pm 2$ \\
\hline Apr & 3 & $64 \pm 7$ & $90 \pm 8$ & $90 \pm 8$ \\
\hline May & 1 & 52 & 100 & 100 \\
\hline Jun & 1 & 32 & 63 & 3 \\
\hline Jul & 0 & - & - & - \\
\hline \multicolumn{5}{|l|}{$\mathbf{H}^{\mathrm{f}}$} \\
\hline Mar & 0 & - & - & - \\
\hline Apr & 1 & 39 & 90 & 90 \\
\hline May & 1 & 64 & 100 & 100 \\
\hline Jun & 1 & 68 & 100 & 99 \\
\hline Jul & 4 & $73 \pm 19$ & $89 \pm 5$ & $87 \pm 5$ \\
\hline \multicolumn{5}{|l|}{$F^{f}$} \\
\hline Mar & 2 & $20 \pm 3$ & $95 \pm 1$ & $95 \pm 1$ \\
\hline Apr & 12 & $50 \pm 6^{b}$ & $94 \pm 2$ & $91 \pm 4$ \\
\hline May & 18 & $63 \pm 4^{\mathrm{a}, \mathrm{b}}$ & $87 \pm 6$ & $78 \pm 8$ \\
\hline Jun & 41 & $86 \pm 6^{\mathrm{a}}$ & $92 \pm 2$ & $85 \pm 4$ \\
\hline Jul & 55 & $70 \pm 4^{\mathrm{a}, \mathrm{b}}$ & $93 \pm 1$ & $91 \pm 2$ \\
\hline
\end{tabular}

indicating that they were both reproductively active during that period. The occurrence of reproductive C. finmarchicus females in early spring is not unique to 2010, as similar or lower abundances have been reported by Plourde et al. (2001). Variable relative abundances of parental species suggest that opportunities for hybridization may vary among years.

The intermediate reproductive phenology of hybrids, when coupled with differences in the ontogeny of males and females sexual maturation, likely explains the apparent asymmetry in the hybridization between C. glacialis and C. finmarchicus. Parent et al. (2012) found that hybrids with C. glacialis mtDNA were relatively more frequent than those with $C$. finmarchicus mtDNA when analyzing CV from the area where hybrids occurred. The same pattern was observed for adult females. In these species, mating occurs at depth after arousal from diapause, and then, adult females quickly migrate to the surface to lay eggs (Mauchline 1998). Male stage CV molt into reproductive adults earlier than females (Conover 1988). Because C. glacialis arise from diapause earlier than C. finmarchicus, the probability that male $C$. finmarchicus mate with female C. glacialis should be higher than for the reciprocal cross. Accordingly, hybrids bearing $C$. glacialis mtDNA should be more frequent, which was in accordance with the present observations.

\section{Fitness}

Calanus hybrids have components of fitness equivalent to those of parental species in the St. Lawrence Estuary. Indeed, egg production, egg hatching success, and egg viability were similar for hybrid and parental species through the pre-bloom and bloom conditions. However, the low abundance and the low population-based egg production rates of hybrid females resulted in a low contribution of hybrids to Calanus biomass at Rimouski Station. These results suggest that the impact of hybridization on the parental species' population size is small in the St. Lawrence Estuary.

However, fitness may vary during the life cycle and interannually. Hybrid and parental species fitness may be different during development. One line of evidence suggesting this difference is that there were $30 \%$ hybrids among stage CV in 2008 (Parent et al. 2012) vs. 10\% hybrids among adult females in 2010. Likewise, the frequencies of highly introgressed individuals were $3 \%$ in 2008 (Parent et al. 2012) and $0.3 \%$ in 2010. Reduction in hybrid frequency between juvenile stage $\mathrm{CV}$ and adult females could be due to genotype-specific mortality and stage-specific hybrid fitness. There are many examples where hybrid fitness varies among developmental stages. For instance, viability is particularly low in early larval stages of Mytilus hybrids, while adult fitness varies across habitats (Bierne et al. 2002, Toro et al. 2004). Similarly, survival seems to vary during maturation in eel hybrids (Gagnaire et al. 2009). To accurately evaluate how environmental variation affects hybrid vs. parental fitness in Calanus, all life stages should be considered. Differences in hybrid proportion observed between samples from 2008 (Parent et al. 2012) and 2010 (this study) in the St. Lawrence Estuary may also be due to interannual variability in abundance and egg production rate of hybrids. Fluctuation in hybrid abundance could be due to variation in the length of the critical temporal 

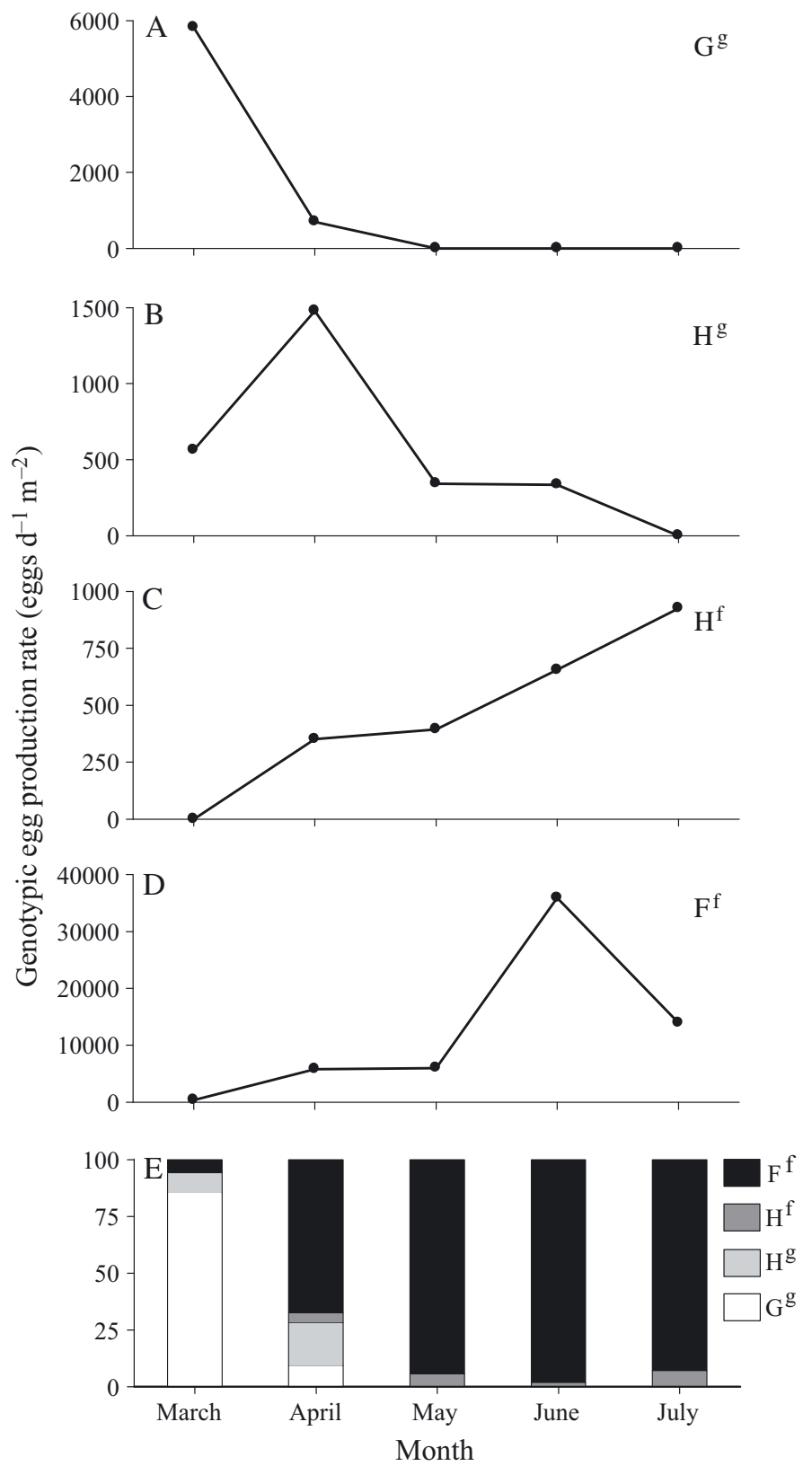

Fig. 4. Temporal variability of (A-D) genotypic egg production rate and (E) relative genotypic egg production rate at Rimouski Station in 2010. Genotypes are identified as in Table 1. $\mathrm{F}^{\mathrm{g}}$ was not represented because it did not lay eggs

window for hybridization caused by variations in overwintering duration and timing of arousal from diapause (Johnson et al. 2008) or to imports from adjacent areas with different proportions of hybrids (Parent et al. 2012). Hybrid abundance could also increase if the peak of primary production is earlier in the year, as observed previously (Plourde et al. 2001). In 2010, the low phytoplankton biomass observed during the maximal abundance of hybrid females may partially explain their low contribution to Calanus biomass. Despite the low contribution of hybrids in 2010, we believe that hybrid abundance and egg production may vary interannually, precluding a definitive conclusion on the effect of hybridization on population size of Calanus species.

\section{Perspectives}

Comparisons of fitness components between hybrids and parents are most likely specific to the St. Lawrence Estuary since they are influenced by environmental conditions. The late spring bloom in the St. Lawrence Estuary (Plourde et al. 2009a) is atypical of oceanic conditions where late winter and late summer blooms are observed. Hence, the late timing of the spring bloom, generally in late May to early June (Plourde et al. 2009a) might limit C. glacialis and hybrid reproductive output. In contrast, the earlier timing of the phytoplankton bloom in the Gulf of St. Lawrence (late May) and on the Newfoundland and Scotian shelves (late March to early April) (Plourde et al. 2009b) could increase the reproductive output of female hybrids. However, such predictions assume that the reproductive phenologies of all genotypes are similar in other regions, which might not be the case. Furthermore, hybrids may not be present in areas where both species are present. A recent study shows that no hybrids were detected (Nielsen et al. 2014) in an area where hybrids were suspected (Parent et al. 2012) due to a short time interval between the reproductive phenologies of $C$. glacialis and C. finmarchicus (Madsen et al. 2001). Thus, more studies are essential to determine hybrid distribution and their contribution to the biomass in order to evaluate the effect of hybridization on Calanus species demography over the entire area where they co-occur.

Acknowledgements. We are particularly grateful to John Nelson, Jean-Éric Tremblay and Julian J. Dodson for inspiring discussions. We also thank the 3 anonymous reviewers for their comments to improve this manuscript. This research was supported by Fisheries and Oceans Canada and by the Natural Sciences and Engineering Research Council Strategic Grant to S.P. and J.T.

\section{LITERATURE CITED}

Arnold ML, Hodges SA (1995) Are natural hybrids fit or unfit relative to their parents? Trends Ecol Evol 10:67-71

Atkinson A (1998) Life cycle strategies of epipelagic copepods in the Southern Ocean. J Mar Syst 15:289-311 
Bierne N, David P, Boudry P, Bonhomme F (2002) Assortative fertilization and selection at larval stage in the mussels Mytilus edulis and M. galloprovincialis. Evolution 56:292-298

> Campbell RG, Wagner MM, Teegarden GJ, Boudreau CA, Durbin EG (2001) Growth and development rates of the copepod Calanus finmarchicus reared in the laboratory. Mar Ecol Prog Ser 221:161-183

- Conover RJ (1988) Comparative life histories in the genera Calanus and Neocalanus in high latitudes of the Northern Hemisphere. Hydrobiologia 167-168:127-142

Conover RJ, Huntley M (1991) Copepods in ice-covered seas-distribution, adaptations to seasonally limited food, metabolism, growth patterns and life cycle strategies in polar seas. J Mar Syst 2:1-41

> Daase M, Falk-Petersen S, Varpe O, Darnis G and others (2013) Timing of reproductive events in the marine copepod Calanus glacialis: a pan-Arctic perspective. Can J Fish Aquat Sci 70:871-884

Edmands S (1999) Heterosis and outbreeding depression in interpopulation crosses spanning a wide range of divergence. Evolution 53:1757-1768

Emery WJ, Thomson RE (1997) Data analysis methods in physical oceanography. Pergamon Press, Oxford

Gagnaire PA, Albert V, Jónsson B, Bernatchez L (2009) Natural selection influences AFLP intraspecific genetic variability and introgression patterns in Atlantic eels. Mol Ecol 18:1678-1691

Galbraith PS, Chassé J, Gilbert D, Larouche P and others (2012) Physical oceanographic conditions in the Gulf of St. Lawrence in 2011. DFO Can Sci Advis Sec Res Doc 2012/023. Fisheries and Oceans Canada, Ottawa

- Hirche HJ, Kattner G (1993) Egg production and lipid content of Calanus glacialis in spring: indication of a food dependent and food independent reproductive mode. Mar Biol 117:615-622

> Johnson C, Leising A, Runge J, Head E, Pepin P, Plourde S, Durbin E (2008) Characteristics of Calanus finmarchicus dormancy patterns in the northwest Atlantic. ICES J Mar Sci 65:339-350

> Kosobokova KN, Hirche HJ (2001) Reproduction of Calanus glacialis in the Laptev Sea, Arctic Ocean. Polar Biol 24: 33-43

Madsen SD, Nielsen TG, Hansen BW (2001) Annual population development and production by Calanus finmarchicus, C. glacialis and C. hyperboreus in Disko Bay, western Greenland. Mar Biol 139:75-93

Mauchline J (1998) The biology of calanoid copepods. In: Blaxter JHS, Southward AJ, Tyler PA (eds) Advances in marine biology, Vol 33. Academic Press, Mid Glamorgan

Miller CB (2004) Biological oceanography. Blackwell Publishing, Singapore

$>$ Niehoff B, Hirche HJ (1996) Oogenesis and gonad maturation in the copepod Calanus finmarchicus and the prediction of egg production from preserved samples. Polar Biol 16:601-612

Nielsen T, Kjellerup S, Smolina I, Hoarau G, Lindeque P (2014) Live discrimination of Calanus glacialis and C. finmarchicus females: Can we trust phenological differ-

Editorial responsibility: Anna Pasternak,

Moscow, Russian Federation ences? Mar Biol 161:1299-1306

> Parent GJ, Plourde S, Turgeon J (2012) Natural hybridization between Calanus finmarchicus and C. glacialis (Copepoda) in the Arctic and Northwest Atlantic. Limnol Oceanogr 57:1057-1066

Parsons TR, Maita Y, Lalli CM (1984) A manual of chemical and biological methods for seawater analysis. Pergamon Press, Oxford

Pasternak AF, Arashkevicha EG, Grotheb U, Nikishinaa AB, Solovyeva KA (2013) Different effects of increased water temperature on egg production of Calanus finmarchicus and C. glacialis. Oceanology (Mosc) 53:547-553

> Plourde S, Runge JA (1993) Reproduction of the planktonic copepod Calanus finmarchicus in the Lower St. Lawrence Estuary: relation to the cycle of phytoplankton production and evidence for a Calanus pump. Mar Ecol Prog Ser 102:217-227

> Plourde S, Joly P, Runge JA, Zakardjian B, Dodson JJ (2001) Life cycle of Calanus finmarchicus in the lower St. Lawrence Estuary: the imprint of circulation and late timing of the spring phytoplankton bloom. Can J Fish Aquat Sci 58:647-658

Plourde S, Maps F, Joly P (2009a) Mortality and survival in early stages control recruitment in Calanus finmarchicus. J Plankton Res 31:371-388

Plourde S, Pepin P, Head E (2009b) Long-term seasonal and spatial patterns in mortality and survival of Calanus finmarchicus across the Atlantic Zone Monitoring Program region, Northwest Atlantic. ICES J Mar Sci 66:1942-1958

Runge JA, Roff JC (2000) The measurement of growth and reproductive rates. In: Harris $\mathrm{R}$, Wiebe $\mathrm{PH}$, Lenz $\mathrm{J}$, Skjoldal HR, Huntley M (eds) ICES zooplankton methodology manual. Academic Press, London, p 401-454

Schnack-Schiel S (2001) Aspects of the study of the life cycles of Antarctic copepods. In: Lopes R, Reid J, Rocha CF (eds) Copepoda: developments in ecology, biology and systematics. Springer Netherlands, Dordrecht, p 9-24

Seehausen O (2004) Hybridization and adaptive radiation. Trends Ecol Evol 19:198-207

> Smith SL (1990) Egg production and feeding by copepods prior to the spring bloom of phytoplankton in Fram Strait, Greenland Sea. Mar Biol 106:59-69

Toro J, Innes DJ, Thompson RJ (2004) Genetic variation among life-history stages of mussels in a Mytilus edulis M. trossulus hybrid zone. Mar Biol 145:713-725

> Tourangeau S, Runge JA (1991) Reproduction of Calanus glacialis under ice in spring in southeastern Hudson Bay, Canada. Mar Biol 108:227-233

Unstad KH, Tande KS (1991) Depth distribution of Calanus finmarchicus and Calanus glacialis in relation to environmental conditions in the Barents Sea. Polar Res 10: $409-420$

> Varpe $\varnothing$ (2012) Fitness and phenology: annual routines and zooplankton adaptations to seasonal cycles. J Plankton Res 34:267-276

> Vogedes D, Varpe O, Soreide JE, Graeve M, Berge J, FalkPetersen S (2010) Lipid sac area as a proxy for individual lipid content of arctic calanoid copepods. J Plankton Res 32:1471-1477

Submitted: November 4, 2014; Accepted: February 10, 2015 Proofs received from author(s): March 16, 2015 